\title{
Identical twins with lumbosacral lipomyelomeningocele
}

\author{
Sara Hanaei, MD, ${ }^{1}$ Farideh Nejat, MD, MPH, ${ }^{1}$ Abolghasem Mortazavi, MD, ${ }^{2}$ Zohreh Habibi, MD, ${ }^{1}$ \\ Arash Esmaeili, MD, ${ }^{1}$ and Mostafa El Khashab, MD, PhD ${ }^{3}$
}

\begin{abstract}
${ }^{1}$ Department of Neurosurgery, Children's Hospital Medical Center, Tehran University of Medical Sciences; ${ }^{2}$ Department of Neurosurgery, Sina Hospital, Tehran University of Medical Sciences, Tehran, Iran; and ${ }^{3}$ Department of Neurosurgery, Hackensack University Medical Center, Hackensack, New Jersey

Lipomyelomeningocele, a congenital spine defect, is presented as skin-covered lipomatous tissue that attaches to the cord in different ways according to its subtypes. Unlike other types of neural tube defects, the exact cause of this birth defect has not been confirmed yet, but it is proposed to be a multifactorial disease with involvement of both genetic and environmental factors. The authors describe identical twins with lipomyelomeningocele of the same subtype and location without any familial history of similar abnormality. Therefore, the same genetic and/or environmental risk factors could have played a part in their condition.

http://thejns.org/doi/abs/10.3171/2014.10.PEDS1494
\end{abstract}

KEY WORDS lipomyelomeningocele; neural tube defects; genetics; risk factors; etiology; congenital

$\mathrm{L}$ IPOMYELOMENINGOCELE (LMMC) is a subtype of closed neural tube defects (NTDs) with an approximate prevalence of 1 per 4000 births in the US and that is more commonly seen among female children..$^{2,15,18}$ This congenital defect occurs as the result of a detachment between cutaneous ectoderm and the neural tube at approximately the 4th week of gestation. Afterward, the neural tube disposal to paraxial mesoderm may incite its differentiation into adipose tissue, and a fatty mass would be the result of its development. ${ }^{2}$ The location of this adipose tissue is often used as a criterion for classification of LMMC, including dorsal, caudal, and transitional types. ${ }^{14}$

Regarding the cause of LMMC, as well as other types of NTDs, it is supported that both environmental and genetic factors play a part in the occurrence of this defect. The environmental risk factors for LMMC might be similar to those for other NTDs including ethnicity, maternal age, ${ }^{14}$ obesity, ${ }^{3,14}$ diabetes mellitus, ${ }^{3,13}$ hyperthermia, consumption of antiseizure drugs like valproic acid, and lack of folic acid consumption. ${ }^{3}$ Regarding the effect of folic acid on etiology of LMMC, whereas some studies failed to show any protective role, ${ }^{6,14}$ a case-control study in our center indicated a significant correlation between protection from defects and maternal folic acid fortification both before and during the first trimester of pregnancy. ${ }^{8}$

To our current knowledge, there is no definite evidence for the role of genetics in the occurrence of LMMC, although it seems that there must be a genetic contribution for this defect because some other kinds of NTDs occur in siblings of LMMC-affected patients. ${ }^{9} 15$ Variants of several genes has been reported in patients with lipomeningocele, LMMC, or spinal lipomas, including MTHFR, CELSRI, and VANGL2. Moreover, a large number of studies have discussed the genes that could be causal in NTDs, including those that are involved in folate pathways, planar cell polarity $(P C P)$ genes, and other probable genes, although the influence of many of them has not been established yet. ${ }^{1,10,12,17}$

We report on identical twins with LMMC of the same subtype and location without previous family history of

ABBREVIATIONS LMMC = lipomyelomeningocele; $M M C=$ myelomeningocele; NTD = neural tube defect.

SUBMITTED February 28, 2014. ACCEPTED October 8, 2014.

INCLUDE WHEN CITING Published online November 14, 2014; DOI: 10.3171/2014.10.PEDS1494.

DISCLOSURE The authors report no conflict of interest concerning the materials or methods used in this study or the findings specified in this paper. 
NTD. Our extensive literature review could not find a similar association. The possible mechanism of familial occurrence of this rare anomaly is discussed as well.

\section{Case Report}

History and Examination

The patients were 3-month-old identical twins born at 34 weeks of gestation, who presented with small lumps in their lumbosacral region at birth; these lumps consisted of normal skin-covered soft-tissue masses without a hairy patch, dermoid sinus, or CSF leakage. The associated skin stigmata were as follows: in the first twin it was a large hyperpigmented nevus on his right lower extremity (Fig. 1A and B), and in the second one it was a small hemangioma on his back and hyperpigmentation of the distal part of the lipomatous mass (Fig. 2 left). No lower limb deformity was identified in the twins, and sensory and motor function of their lower limbs seemed normal.

\section{Family History}

The twins were the first offspring of a consanguineous marriage without a history of either LMMC or other types of NTDs in first- to third-degree relatives. Their mother was a 27-year-old woman with a body mass index of 23.6 before pregnancy and no history of insulin-dependent diabetes mellitus or hyperthermia during pregnancy. However, she had experienced impaired glucose tolerance in the 3 rd month of gestation, which was controlled by diet. She had also used folic acid from the 3rd month of gestation but had no history of treatment with antiseizure medication.

\section{Radiological Findings}

Magnetic resonance imaging of both infants confirmed an extraspinal lipomatous mass in continuity with intradural lipoma, which was attached to the cord at the L5-S1 vertebral levels (Figs. 1C and 2 right). Urological evaluation performed using a urodynamic study showed neurogenic type bladder that was managed with medical treatment.

\section{Operation}

The patients underwent untethering L5/S1 laminotomy and debulking of the fatty mass. The lipomatous tissue was
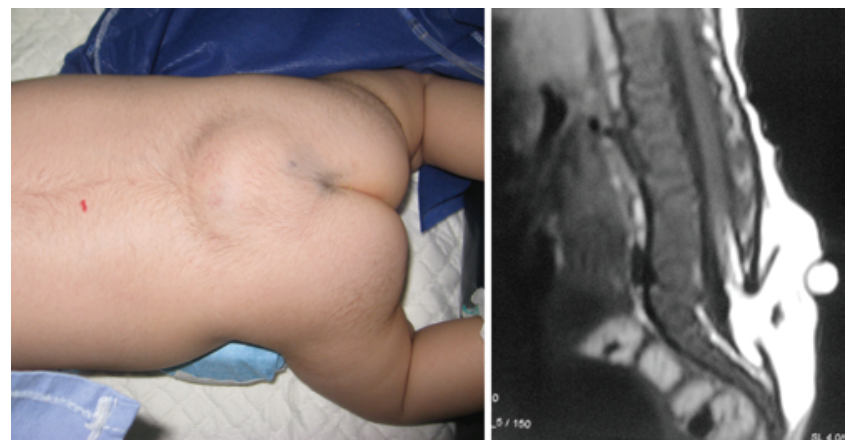

FIG. 2. Left: Photograph of the second twin showing the soft-tissue mass in the lumbosacral area associated with a small hemangioma and hyperpigmentation at the distal part of the mass. Right: Lumbosacral MRI study confirming intradural attachment of the lipoma to the cord at the L5-S1 vertebral levels, similar to the results in the first twin's MRI study. Figure is available in color online only.

attached to the cord in a way that led to diagnosis of transitional type LMMC. The cord and rootlets were untethered from lipomatous tissue and adhesion bands. Lipomatous tissue resection was performed with a Cavitron ultrasonic surgical aspirator, and a layer of this tissue was left on the cord at the end of surgery. Afterward, the fatty thick filum was cut at the distal part of the dural sac, and the neural placode was reconstructed to a tube-shaped structure via pial suturing. The intraoperative findings were completely similar in both infants.

\section{Postoperative Course}

The infants had an uncomplicated postoperative period and were discharged 6 days after operation. During a 10-month follow-up period, neither child had new complaints. Both could stand without help at 12 months of age and walk a few steps at 13 months. Neither vesicoureteric reflux nor postvoiding residual volume was found in further urological follow-up. Spinal MRI studies performed at the age of 1 year did not show any new abnormalities (Fig. 3).

\section{Discussion}

Neural tube defects are a heterogeneous group of anomalies in which both genetic and environmental factors are
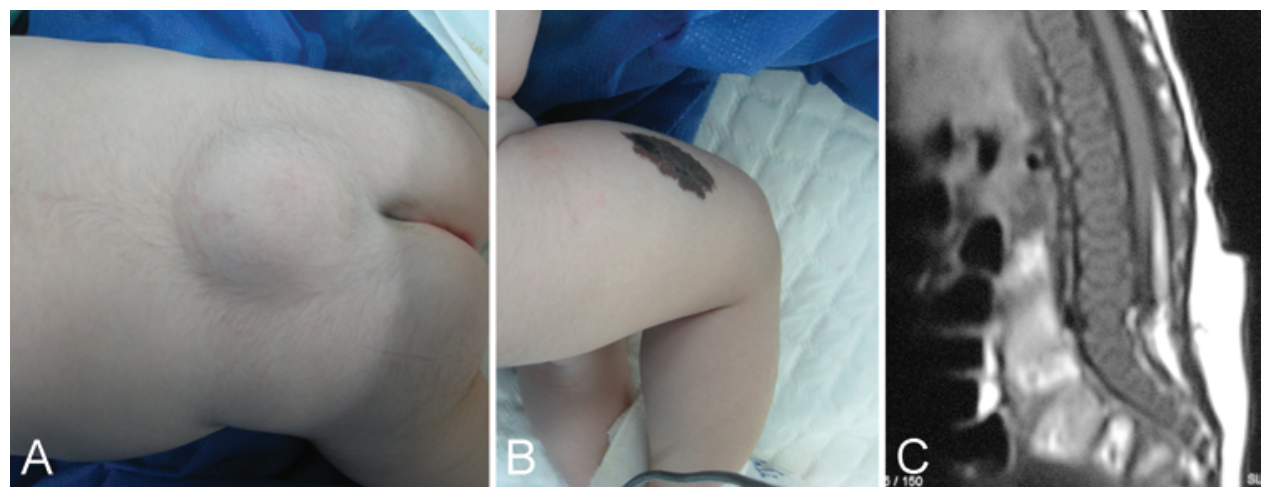

FIG. 1. A and B: Photographs of the first twin showing the normal skin-covered soft-tissue mass in the lumbosacral area associated with a large hyperpigmented nevus in his right lower extremity. C: Lumbosacral MRI study confirming intradural lipoma attached to the cord at the L5-S1 vertebral levels. Figure is available in color online only. 


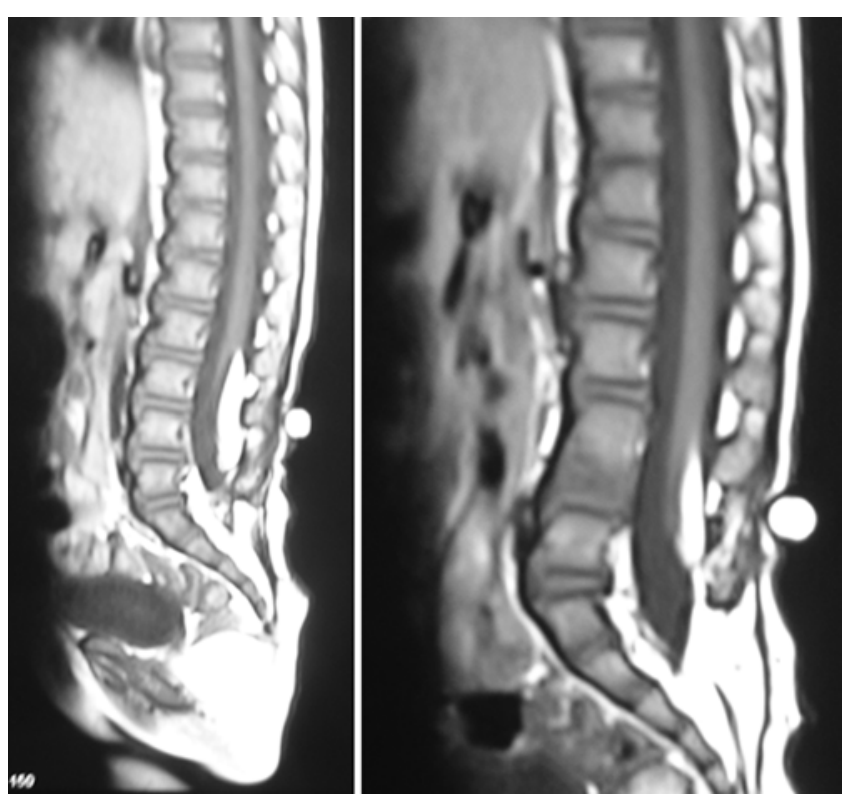

FIG. 3. Postoperative sagittal T1-weighted MRI views of the twins. The image in the left panel was obtained in the first twin, corresponding to Fig. $1 \mathrm{C}$, and the one in the right panel was obtained in the second twin.

proposed to have significant roles in the occurrence of these defects. ${ }^{15}$ Regarding the high prevalence of myelomeningocele (MMC), the risk factors were extensively studied for this anomaly but LMMC, as a distinct entity, has not been evaluated substantially. Because it is a big concern for the families, the recurrence rate of NTD has been studied specifically for MMC, but the literature lacks significant information about LMMC recurrence in families. ${ }^{14-16}$

Recurrent risk of NTD has been reported in families with NTD subtypes. In an American study, the siblings of patients with LMMC have been affected by MMC, anencephaly, or fatty filum, but no recurrence of LMMC has been observed in this population. Accordingly, it has been suggested that the same genetic pattern might be involved in both open and closed NTDs. ${ }^{15}$ There are two records of LMMC recurrence: one in an American family with two affected children, in which the recurrence had been diagnosed prenatally in the second pregnancy, ${ }^{16}$ and the other in a family of Portuguese descent, in which the mother gave birth to an LMMC-affected male baby after a female offspring was born with sacral LMMC and tethered cord. ${ }^{9}$ There is also a report of MMC in an Indian set of nonidentical twins of different sexes and with the presence of hydrocephalus in the female twin. ${ }^{4}$ Furthermore, parents with spina bifida occulta have been more likely to have a child with spina bifida cystica, ${ }^{11}$ which might suggest a recessive inheritance of NTDs. ${ }^{9,11}$ Moreover, maternal first cousins, specifically female offspring of maternal aunts, are more likely to have NTDs. This may indicate higher involvement of maternal genes in embryonic development than the fetal genes, and mitochondrial inheritance or genomic imprinting could be other possible explanations for this inheritance pattern. ${ }^{5,7}$

Embryonic gene expression, including those involved in NTDs, are affected by maternal diabetes during pregnancy. Thus, inappropriate gene regulation and expression might predispose the embryo to develop a neural tube defect, and maternal diabetes would be proposed as an etiologic risk factor for NTD, although there is no evidence that it has a direct effect on LMMC. ${ }^{13}$

It has been demonstrated that a folic acid regimen reduces the risk of NTDs. Therefore, levels of folic acid cycle members as well as polymorphisms in their genes might play roles in the occurrence of NTDs through altering enzyme activity. ${ }^{17,19}$

In this report we present a set of identical twins with LMMC in whom both fatty masses were surprisingly the same in terms of type and location. Possible environmental risk factors such as lack of maternal folic acid consumption before and during the first trimester of pregnancy and also the potential genes were the same for both twins. Therefore, the effect of either genetic or environmental factors, or the combination of both, could have played a part in this condition. Unfortunately, we were unable to provide genetic assessment in our center to find probable gene mutations. However, monozygosity and the consanguineous marriage could somehow advocate effects of genetics in these particular cases.

\section{References}

1. Allache R, De Marco P, Merello E, Capra V, Kibar Z: Role of the planar cell polarity gene CELSR 1 in neural tube defects and caudal agenesis. Birth Defects Res A Clin Mol Teratol 94:176-181, 2012

2. Blount JP, Elton S: Spinal lipomas. Neurosurg Focus 10(1): E3, 2001

3. Botto LD, Moore CA, Khoury MJ, Erickson JD: Neural-tube defects. N Engl J Med 341:1509-1519, 1999

4. Budhiraja S, Dahiya P, Ghei M, Gathwala G: Neural-tube defect in dizygotic twins. Pediatr Surg Int 18:211-212, 2002

5. Byrne J: Birth defects among maternal first cousins in Irish families with a neural tube defect. Ir J Med Sci 179:375380, 2010

6. De Wals P, Van Allen MI, Lowry RB, Evans JA, Van den Hof MC, Crowley M, et al: Impact of folic acid food fortification on the birth prevalence of lipomyelomeningocele in Canada. Birth Defects Res A Clin Mol Teratol 82:106-109, 2008

7. Deak KL, Siegel DG, George TM, Gregory S, Ashley-Koch A, Speer MC: Further evidence for a maternal genetic effect and a sex-influenced effect contributing to risk for human neural tube defects. Birth Defects Res A Clin Mol Teratol 82:662-669, 2008

8. Esmaeili A, Hanaei S, Fadakar K, Dadkhah S, Arjipour M, Habibi Z, et al: Risk factors associated with lipomyelomeningocele: a case-control study. Pediatr Neurosurg 49:202207, 2013

9. Kannu P, Furneaux C, Aftimos S: Familial lipomyelomeningocele: a further report. Am J Med Genet A 132A:90-92, 2005

10. Kibar Z, Salem S, Bosoi CM, Pauwels E, De Marco P, Merello E, et al: Contribution of VANGL2 mutations to isolated neural tube defects. Clin Genet 80:76-82, 2011

11. Lorber J, Levick K: Spina bifida cystica. Incidence of spina bifida occulta in parents and in controls. Arch Dis Child 42:171-173, 1967

12. Robinson A, Escuin S, Doudney K, Vekemans M, Stevenson $\mathrm{RE}$, Greene ND, et al: Mutations in the planar cell polarity genes CELSR1 and SCRIB are associated with the severe neural tube defect craniorachischisis. Hum Mutat 33:440 447, 2012 
13. Salbaum JM, Kappen C: Neural tube defect genes and maternal diabetes during pregnancy. Birth Defects Res A Clin Mol Teratol 88:601-611, 2010

14. Sarris CE, Tomei KL, Carmel PW, Gandhi CD: Lipomyelomeningocele: pathology, treatment, and outcomes. A review. Neurosurg Focus 33(4):E3, 2012

15. Sebold CD, Melvin EC, Siegel D, Mehltretter L, Enterline DS, Nye JS, et al: Recurrence risks for neural tube defects in siblings of patients with lipomyelomeningocele. Genet Med 7:64-67, 2005

16. Seeds JW, Powers SK: Early prenatal diagnosis of familial lipomyelomeningocele. Obstet Gynecol 72:469-471, 1988

17. van der Linden IJ, Afman LA, Heil SG, Blom HJ: Genetic variation in genes of folate metabolism and neural-tube defect risk. Proc Nutr Soc 65:204-215, 2006

18. Wykes V, Desai D, Thompson DN: Asymptomatic lumbosacral lipomas - a natural history study. Childs Nerv Syst 28:1731-1739, 2012

19. Yang M, Yang L, Qi L, Guo Y, Lin X, Zhang Y, et al: Association between the methionine synthase A2756G poly- morphism and neural tube defect risk: a meta-analysis. Gene 520:7-13, 2013

\section{Author Contributions}

Conception and design: Nejat, Habibi, El Khashab. Acquisition of data: Mortazavi, Habibi. Analysis and interpretation of data: Nejat, Habibi. Drafting the article: Nejat, Hanaei, Mortazavi, Esmaeili. Critically revising the article: Esmaeili, El Khashab. Reviewed submitted version of manuscript: Nejat, Mortazavi, Habibi, Esmaeili, El Khashab. Approved the final version of the manuscript on behalf of all authors: Nejat. Statistical analysis: Hanaei. Administrative/technical/material support: Nejat, Habibi. Study supervision: Nejat, Habibi.

\section{Correspondence}

Farideh Nejat, Children's Hospital Medical Center, Tehran University of Medical Sciences, Gharib St., Tehran 14155-7854, Iran.email: nejat@sina.tums.ac.ir. 